\title{
Drug loading, dispersion stability, and therapeutic efficacy in targeted drug delivery with carbon nanotubes
}

\author{
Elena Heister $^{1,2}$, Vera Neves ${ }^{1,2}$, Constanze Lamprecht ${ }^{3}$, S. Ravi P. Silva ${ }^{2}$, Helen M. Coley ${ }^{1}$, and \\ Johnjoe McFadden,
}

\author{
${ }^{1}$ Faculty of Health and Medical Sciences, University of Surrey, Guildford, GU2 7XH, UK \\ ${ }^{2}$ Nanoelectronics Centre, Advanced Technology Institute, University of Surrey, Guildford, GU27XH, \\ UK \\ ${ }^{3}$ Institute of Biophysics, Johannes Kepler University, Altenberger Strasse 69, A-4040 Linz, Austria
}

\begin{abstract}
We have designed a drug delivery system for the anti-cancer drugs doxorubicin and mitoxantrone based on carbon nanotubes, which is stable under biological conditions, allows for sustained release, and promotes selectivity through an active targeting scheme. Carbon nanotubes are particularly promising for this area of application due to their high surface area, allowing for high drug loading, and their unique interaction with cellular membranes. We have taken a systematic approach to PEG conjugation in order to create a formulation of stable and therapeutically effective CNTs. The presented drug delivery system may be a means of improving cancer treatment modalities by reducing drug-related side effects.
\end{abstract}

\section{Introduction}

Cancer is amongst the top three killers in modern society, next to heart and cerebrovascular diseases. In 2009, approximately eight million people died from cancer worldwide according to the WHO. The two chemotherapeutic drugs examined in this study, doxorubicin and 
mitoxantrone, are frequently used in the clinic for the treatment of a range of solid tumors, including breast and prostate cancers. However, both drugs are associated with severe, sometimes fatal cardiotoxicity due to a lack of target specificity [1]. Several attempts have been made to reduce this serious side effect, for example by liposomal encapsulation of doxorubicin (Myocet ${ }^{\circledR}$ ) or liposomal encapsulation plus additional PEGylation (Doxil®). Additionally, active drug targeting strategies are being developed to further enhance selectivity. In recent years, carbon nanotubes (CNTs) have emerged as promising candidates for a multimodal drug delivery system. They not only allow for the attachment of multiple copies of drug molecules, but can also be equipped with targeting agents and stealth molecules to evade clearance by the immune system. Furthermore, they hold several potential advantages over other nano-sized delivery systems, such as an exceptionally high drug loading capacity due to their high surface area and the possibility for incorporating additional therapeutic and diagnostic moieties, either on the surface or their inner cavity. In addition, they interact with cellular membranes in a unique way: some types of CNTs have been reported to enter mammalian cells by an endocytosis-independent, "needle-like" penetration mechanism, which allows for direct cytoplasmic delivery of therapeutic payloads [2, 3]. A number of studies have already reported successful delivery of anti-cancer drugs to human cancer cells or tumor xenografts by means of carbon nanotubes [4-9]. Amongst these, doxorubicin has emerged as a favored drug candidate due to its inherent fluorescence, facilitating cellular imaging and quantitative assays based on absorption or fluorescence spectroscopy. However, no study to date has reported the delivery of mitoxantrone by carbon nanotubes, which is also a fluorescent anti-cancer drug with a similar mechanism of action to that of doxorubicin.

In this article, we focus on the fine-tuning of the functionalisation chemistry of carbon nanotubes for drug delivery applications, in particular with regard to therapeutic efficacy, 
biocompatibility and stability. We first investigated how the binding conditions during the drug loading step (e.g. pH, temperature, and light) influence the therapeutic activityof the drugs and, in the case of $\mathrm{pH}$, their binding onto nanotubes, and took a systematic approach to PEG conjugation in order to achieve maximal dispersion stability. We then demonstrated pHdependent release of the drugs, which promoted their release inside cells upon internalisation. We also studied drug release in cellular growth medium prior to cellular uptake, which is a possible mechanism for premature drug release. Cellular uptake and fate of the designed drug delivery vectors was visualised by confocal microscopy. Finally, the therapeutic efficacy of the drug-CNT complexes was evaluated by in vitro cell viability assays. The results indicate that interestingly, a stable dispersion is of minor importance for the therapeutic success of the system. Furthermore, the attachment of folate as a targeting agent significantly enhanced cytotoxicity, thereby achieving higher cell killing at lower drug concentrations combined with a certain selectivity for cancerous cells, as folate receptors are significantly upregulated by a broad spectrum of human cancers [10].

\section{Material and Methods}

\subsection{Material}

The applied single-walled CNTs (SWCNTs) were produced by SouthWest NanoTechnologies (Norman, OK, U.S.A.) using the CoMoCAT® method (SWeNT® SG 65) and were supplied by Sigma-Aldrich (Poole, UK), Order No. 70414, Lot No. MKBB63098. Tube diameters were $0.8 \pm 0.1 \mathrm{~nm}$, carbon content was $>90 \%$ by weight, $>50 \%$ of tubes were $(6,5)$ chirality, $>90 \%$ of tubes were semiconducting. RNA derived from baker's yeast was purchased from Sigma-Aldrich (Poole, UK), Order No. R6750. The various polyethylene glycol (PEG) derivates used comprised polyoxyethylene bis(amine) Mw2000 (PEG 2000$\mathrm{NH}_{2}$ ), O-(2-Aminoethyl)-O'-(2-carboxyethyl)polyethylene glycol 3,000 hydrochloride (PEG 
3000-COOH), and poly(ethylene oxide), 4-arm, amine terminated (branched PEG 2500$\mathrm{NH}_{2}$ ), purchased from Sigma-Aldrich (Poole, UK); furthermore carboxy-PEG 8 -amine (PEG 440-COOH), obtained from Thermo Fisher Scientific (Cramlington, UK), and 1,2-distearoylsn-glycero-3-phosphoethanolamine-N-[amino(polyethylene glycol)-2000] (ammonium salt) (PL-PEG 2000-NH ${ }_{2}$ ) from Avanti Polar Lipids Inc. (Alabaster, US). All other chemicals were purchased from Sigma-Aldrich (Poole, UK) and used without further treatment.

\subsection{Purification and acid oxidation}

SWCNTs were first purified by incubation in concentrated nitric acid at $95{ }^{\circ} \mathrm{C}$ for $2 \mathrm{~h}$. In a second step, the sample was oxidised by incubation in a 3:1 mixture of concentrated nitric and sulfuric acid at $95{ }^{\circ} \mathrm{C}$ for $2 \mathrm{~h}$. Afterwards, the oxidised SWCNTs (oxSWCNTs) were washed by vacuum-assisted filtration using $0.2 \mu \mathrm{m}$ polycarbonate filters (Whatman Ltd.) until the eluate was clear and of neutral $\mathrm{pH}$. Oxidation debris was removed by washing with sodium hydroxide $(0.01 \mathrm{M})$ and three centrifugation steps at $75,000 \mathrm{~g}$ were performed to remove big agglomerates and bundles. The concentration of the resulting dispersion was determined gravimetrically by filtering a known volume of oxSWCNT suspension using 0.2 $\mu \mathrm{m}$ polycarbonate filters (Whatman Ltd.), drying the filter for $1 \mathrm{~h}$ at $110^{\circ} \mathrm{C}$, and weighing the amount of oxSWCNTs on the filter paper using a microbalance. Finally, the concentration was adjusted to $200 \mu \mathrm{g} / \mathrm{mL}$.

\subsection{Sample characterisation}

The obtained oxSWCNTs were then characterised by atomic force microscopy (AFM), UV/vis absorption spectroscopy and Raman spectroscopy. For AFM sample preparation, oxSWCNTs were diluted with water to obtain a concentration of $10 \mu \mathrm{g} / \mathrm{mL}$ and a droplet was placed onto a freshly cleaved mica substrate $\left(1 \mathrm{~cm}^{2}\right)$ and dried in air. AFM measurements 
were performed using a PicoPlus instrument (Agilent Technologies, Chandler, AZ, USA) operated in contact mode at room temperature with a lateral scan rate of $1-1.5 \mathrm{~Hz}$ at 512 lines. Data analysis was carried out using "Gwyddion 2.9”, a free SPM data visualisation and imaging tool released under the GNU General Public License. UV/vis absorption spectroscopy was carried out using a Helios Alpha UV/Vis spectrophotometer from Thermo Scientific. Raman spectroscopy measurements were performed using a Renishaw microRaman instrument at an excitation wavelength of $785 \mathrm{~nm}$. Acid-base titration to determine the number of total acidic sites was carried out as described in the supporting information.

\subsection{Optimisation of the functionalisation procedure}

\subsubsection{Degradation of the two drugs as a function of $\mathrm{pH}$, light, and temperature}

$0.5 \mathrm{mM}$ doxorubicin or mitoxantrone solutions were prepared in $100 \mathrm{mM}$ sodium phosphate buffers at $\mathrm{pH}$ 5-9 and incubated in the fridge in darkness or at room temperature in daylight for 3 days. Afterwards, Hela cells were incubated with various drug solutions at concentrations ranging from $0.05 \mu \mathrm{M}$ up to $10 \mu \mathrm{M}$ for $72 \mathrm{~h}$ (doxorubicin samples) or $96 \mathrm{~h}$ (mitoxantrone samples). Finally, the cytotoxicity of the drug solutions were tested by MTT cell viability assays and $\mathrm{IC}_{50}$ values obtained by fitting using the four-parameter model.

\section{Effect of pH on drug binding}

$5 \mu \mathrm{g}$ oxSWCNTs were mixed with $0.5 \mathrm{mM}$ doxorubicin or mitoxantrone and $5 \mathrm{mM}$ sodium phosphate buffer at $\mathrm{pH} 5,6,7,8$, or 9 . Next, the samples were incubated for $24 \mathrm{~h}$ at $4{ }^{\circ} \mathrm{C}$ and subsequently filtered using $300 \mathrm{kDa}$ Pall Nanosep ${ }^{\circledR}$ centrifugal devices with Omega ${ }^{\mathrm{TM}}$ membranes. The filtrate and the flow-through of the first wash were collected for UV/vis analyis (at $479 \mathrm{~nm}$ for doxorubicin or at $550 \mathrm{~nm}$ for mitoxantrone) in order to determine the 
amount of unbound drug. The wavelength of $550 \mathrm{~nm}$ was chosen because the absorbance values at the maxima (608 and $660 \mathrm{~nm})$ were outside the linear range $(>0.8)$.

\subsubsection{Effect of PEG type on drug loading and dispersion stability}

To examine the effect of the PEG type on drug loading and dispersion stability, oxSWCNTs were "PEGylated" with various PEG formulations as described in the following: $100 \mu \mathrm{g}$ oxSWCNTs were mixed with $5 \mathrm{mM}$ sodium phosphate buffer $\mathrm{pH} 7.6$ and $20 \mathrm{mM}$ EDC/50 $\mathrm{mM}$ sulfo-NHS and incubated for $15 \mathrm{~min}$ at room temperature while stirring. Next, $1 \mathrm{mM}$ preparations of PEG 2000- $\mathrm{NH}_{2}$, PEG 440-COOH, PEG 3000-COOH, branched PEG 2500$\mathrm{NH}_{2}$, or PL-PEG 2000- $\mathrm{NH}_{2}$ were added and the samples incubated for $2 \mathrm{~h}$ at room temperature while stirring. Note that in the case of PL-PEG no EDC/sulfo-NHS was used as the functionalisation is non-covalent. Finally, unbound PEG was removed by filtration through $0.2 \mu \mathrm{m}$ polycarbonate filters (Whatman Ltd.) and the PEGylated nanotubes

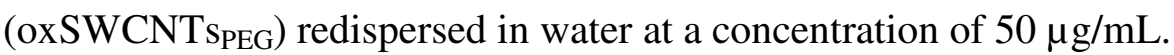

Next, drug binding and dispersion stability was investigated by mixing $10 \mu \mathrm{g}$ oxSWCNTS PEG $_{\text {S }}$ with $100 \mu \mathrm{M}$ doxorubicin or mitoxantrone and $5 \mathrm{mM}$ sodium phosphate buffer $\mathrm{pH} 8$ (doxorubicin samples) or $\mathrm{pH} 9$ (mitoxantrone samples). After an incubation period of $24 \mathrm{~h}$ at $4{ }^{\circ} \mathrm{C}$, all samples were split in half. The first portions were used to determine the amount of unbound drug by filtration through $300 \mathrm{kDa}$ Pall Nanosep® centrifugal devices with Omega $^{\mathrm{TM}}$ membranes. Both the filtrates and the flow-throughs of the first wash were collected for UV/vis analysis (at $479 \mathrm{~nm}$ for doxorubicin or at $550 \mathrm{~nm}$ for mitoxantrone). A sample of the same composition but without carbon nanotubes served as the $100 \%$ value. The second portions were used to determine the dispersion stability (weight percentage of dispersed tubes). Therefore, the samples were centrifuged at 12,000g for $5 \mathrm{~min}$ and the supernatants analysed by UV/vis spectroscopy at $730 \mathrm{~nm}$ (doxorubicin samples) or at $850 \mathrm{~nm}$ 
(mitoxantrone samples). Note that both wavelengths are outside the absorbance range of the drugs to ensure measuring solely the absorbance signal of the SWCNTs.

\subsubsection{Effect of PEG density on drug loading}

$100 \mu \mathrm{g}$ oxSWCNTs were PEGylated in the same way as described above, except that instead of various different PEG formulations, only branched PEG 2500- $\mathrm{NH}_{2}$ was used (amounts added ranged from $5 \mu \mathrm{mol}$ to $0.1 \mu \mathrm{mol}$ ). Considering that the amount of total acidic sites is about $0.15 \mu \mathrm{mol} / 100 \mu \mathrm{g}$ oxSWCNTs (as determined in the supporting information), this corresponds to ratios of PEG molecules to acidic sites between 33.3 and 0.7. The measurement of drug binding and dispersion stability was also carried out in the same way as described above.

\subsection{Drug release over time at different conditions}

In order to measure drug release over time at different conditions, the two drugs doxorubicin and mitoxantrone were loaded onto oxSWCNTs functionalised with branched PEG 2500$\mathrm{NH}_{2}$ at a drug/CNT weight ratio of 1:2, which guarantees $100 \%$ drug binding. After incubation over night at $4{ }^{\circ} \mathrm{C}$, the samples were mixed with $100 \mathrm{mM}$ sodium phosphate buffer $\mathrm{pH}$ 5.5/7.4 or cellular growth medium (MEM, phenol red-free) and incubated at $37{ }^{\circ} \mathrm{C}$ for $24 \mathrm{~h}, 48 \mathrm{~h}$, or $72 \mathrm{~h}$. After each time point, $500 \mu \mathrm{L}$ of each sample were filtered using 300 $\mathrm{kDa}$ Pall Nanosep® centrifugal devices and the amount of drug in the eluates analysed by $\mathrm{UV} / \mathrm{vis}$ absorption spectroscopy (at $479 \mathrm{~nm}$ for doxorubicin or at $608 \mathrm{~nm}$ for mitoxantrone).

\section{6. $\quad$ Functionalisation of PEGylated oxSWCNTs with folic acid and fluorescein} $200 \mu \mathrm{g}$ folic acid was activated with $20 \mathrm{mM}$ EDC/50 mM sulfo-NHS for $15 \mathrm{~min}$ at room temperature. For attachment of folic acid only, $100 \mu \mathrm{g}$ oxSWCNTSPEG were added and the 
mixture stirred for $2 \mathrm{~h}$ at room temperature. For attachment of both folic acid and fluorescein, $200 \mu \mathrm{g}$ NHS-fluorescein was added to the mixture prior to incubation, corresponding to a molar ratio of approximately 1:1. Finally, unreacted folic acid and fluorescein were removed by filtration through $0.2 \mu$ m polycarbonate filters (Whatman Ltd.) and the folate-targeted,

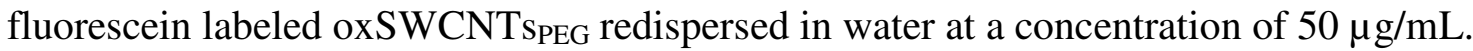

\section{Cell culture \& cell viability studies}

Hela cells were cultured in Eagle's Minimal Essential Medium (MEM) supplemented with Lglutamine (2 mM), 10\% fetal bovine serum, non-essential amino acids ( $0.1 \mathrm{mM})$, and penicillin/streptomycin (100 units/mL penicillin and $100 \mu \mathrm{g} / \mathrm{mL}$ streptomycin) for use in a $5 \% \mathrm{CO}_{2}$ in air atmosphere. All cell culture reagents were obtained from Invitrogen (Paisley, UK). For the targeting experiments, the cells were cultured in folate-free RPMI medium with the same supplements for several cycles to induce overexpression of the folate receptor. In order to perform a cell viability assay, cultured cells in single cell suspension were seeded at a density of $10^{4}$ cells per well and incubated for $24 \mathrm{~h}$. The following day, dilution series of the respective drug-SWCNT samples in cellular growth medium were prepared and appropriate volumes added to the wells to obtain final drug concentrations of 5000, 2000, $1000,500,200,100,50$, and $20 \mathrm{nM}$. After an incubation period of 96 hours, the old culture medium containing the nanotube formulations was replaced with fresh medium to reduce false positive results in cytotoxicity assays [11] and cell viability evaluated by means of the MTT and WST assay. Each sample was tested in quadruplicate. Dose-response curves were generated by plotting cell viability against drug concentration. In order to obtain $\mathrm{IC}_{50}$ values (i.e. the drug concentrations, at which $50 \%$ of the cell population is killed), curves were fitted using the four-parameter model, a widely-used model for fitting sigmoidal dose-response curves. 


\subsection{Confocal microscopy}

Cultured cells in single cell suspension were seeded into 24-well tissue culture plates containing cover slips at a density of 75,000 cells per well. After an incubation period of $24 \mathrm{~h}$ under standard tissue culture conditions, the medium in the wells was replaced with a 1:1 mixture of the respective nanotube sample in cell medium and the plate incubated for $1 \mathrm{~h}, 3$ $\mathrm{h}$, or $5 \mathrm{~h}$ at $37^{\circ} \mathrm{C}$. Afterwards, the medium was aspirated off, the cells washed twice with PBS and incubated with $4 \%$ formaldehyde for 10 min. Next, ToPro3 nuclear stain in a 1:10,000 dilution $(1 \mathrm{~mL})$ was added to each well and the plate left to incubate for $10 \mathrm{~min}$. Finally, after abundant washing, the cover slips were mounted onto glass slides using VECTASHIELD® fluorescent mounting medium and sealed with nail polish. Confocal microscopy was carried out using a Zeiss LSM 510 confocal microscope in multichannel mode. Fluorescein-labeled structures were excited at $488 \mathrm{~nm}$ and emission detected at 500$550 \mathrm{~nm}$, doxorubicin excited at $488 \mathrm{~nm}$ and detected at 650-710 nm, and TOPRO excited at $633 \mathrm{~nm}$ and detected at $650-710 \mathrm{~nm}$.

\section{Results and Discussion}

Initially, the applied sample of oxidised, single-walled CNTs (oxSWCNTs) was characterised by various techniques and we investigated how the binding conditions during the drug loading step (e.g. pH, temperature, and light) influence the therapeutic activityof the drugs. Next, binding of the drugs to oxSWCNTs was studied in respect to $\mathrm{pH}$, and a systematic approach to PEG conjugation was undertaken in order to achieve maximal dispersion stability. After demonstrating $\mathrm{pH}$-dependent drug release we visualized cellular uptake of drug-loaded oxSWCNTSPEG by confocal microscopy and finally compared their therapeutic 
efficacy to that of the free drugs and to drug-loaded oxSWCNTSPEG conjugated to the targeting agent folate.

\subsection{Preparation and characterisation of the applied carbon nanotubes}

In a previous study we compared five different types of oxidised CNTs with regard to their dispersion stability. Data suggested that oxSWCNTs produced by the CoMoCAT® method exhibited the highest dispersion stability, attributed to their short aspect ratio after acid oxidation [12]. We thus selected this nanotube sample as the most promising candidate for the development of a CNT-based drug delivery system.
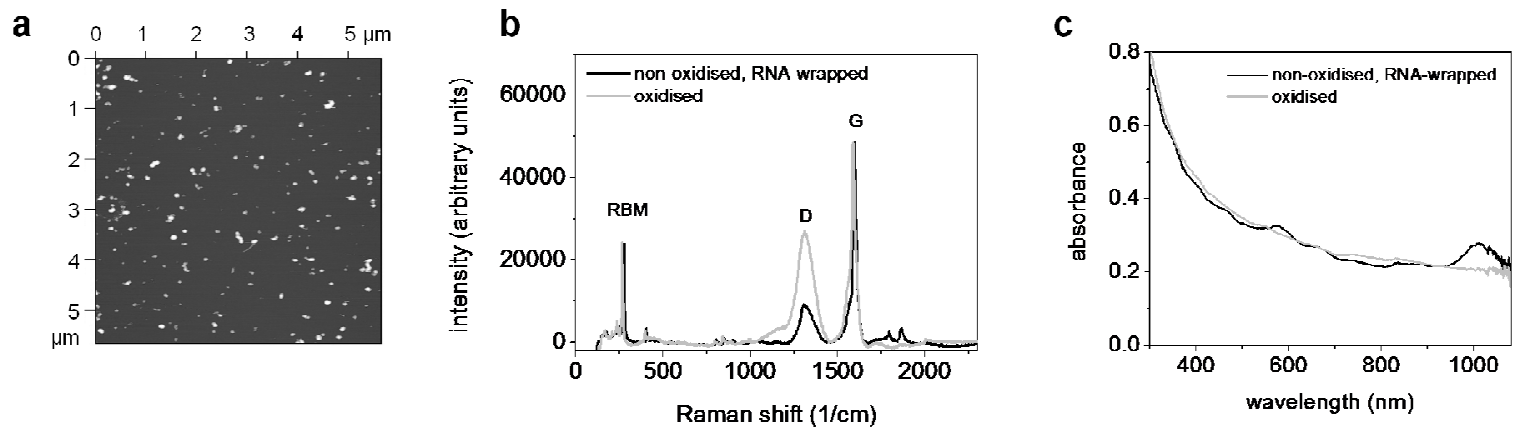

Figure 1 Characterisation of the used oxSWCNTs by a) atomic force microscopy, b) Raman spectroscopy, and c) UV/vis absorption spectroscopy.

Figure 1 shows the characterisation results after analysis by atomic force microscopy (AFM), Raman spectroscopy, and UV/vis absorption spectroscopy. The mean particle size of the oxSWCNTs was about $126 \pm 8 \mathrm{~nm}$, as determined by phase analysis light scattering (PALS) [12]. Considering that pristine SWCNTs are between 450 and $2000 \mathrm{~nm}$ long (mode at 900 $\mathrm{nm}$ ) according to the manufacturer, this demonstrates that the acid treatment has shortened the nanotubes by more than $90 \%$, which is also evident in the AFM image (Figure 1a). 
Further AFM analysis of this sample including higher magnification images can be found elsewhere [12]. Their Raman spectrum (Figure 1b) featured three prominent peaks: the radial breathing mode $(\mathrm{RBM})$ at $263 \mathrm{~cm}^{-1}$, which is inversely proportional to the tube diameter, the disorder-related D-band at $1313 \mathrm{~cm}^{-1}$, and the graphitic G-band at $1590 \mathrm{~cm}^{-1}$. The intensity ratio of the D- to the G-band is an indicator of the structural disorder originating from the formation of in the graphitic structure. In the case of the oxSWCNTs examined in this study, the $\mathrm{I}_{\mathrm{D}} / \mathrm{I}_{\mathrm{G}}$ ratio was 0.19 for pristine $\mathrm{SWCNTs}$ and 0.55 for oxidised $\mathrm{SWCNTs}$, which indicated that the density of defects/functional groups was higher after oxidation. This also explains why the typical UV/vis features of non-oxidised SWCNTs were absent after acid oxidation (Figure 1c). It should furthermore be noted that the sample had been washed with $\mathrm{NaOH}$ and $\mathrm{HCl}$ after acid oxidation and was thus free of oxidation debris [13].

\subsection{Fine-tuning of the functionalisation procedure}

\subsubsection{Degradation of doxorubicin and mitoxantrone as a function of $\mathrm{pH}$, light, and} temperature

The first experiment was designed to determine the optimal $\mathrm{pH}$ and temperature conditions for the two drugs. It is well-known that both doxorubicin and mitoxantrone are not ideal drugs from an analytical point of view. Doxorubicin is known to self-associate in concentrated solutions, is liable to photolytic decomposition and degrades at unfavorable $\mathrm{pH}$ conditions [14]. It is most stable at $\mathrm{pH} 4$ and converts into the 7-hydroxyaglykone (detached amino sugar residue) in more acidic conditions and destabilises at basic $\mathrm{pH}$ due to enolisation of the $\mathrm{C} 9$ side chain. Similarly, mitoxantrone is also most stable at $\mathrm{pH} 4$ and shows accelerated degradation at higher $\mathrm{pH}$, under UV irradiation, and at higher temperatures [15]. It furthermore forms precipitates upon refrigeration, which redissolve after warming to room temperature without a loss of efficacy [16]. 
Drug delivery experiments are usually performed with a $\mathrm{pH}$ range of 5.5-7.5 to maintain cell viability, yet we and others [5] found that the binding of doxorubicin and mitoxantrone to CNTs works best at high $\mathrm{pH}$, at which the drugs are deprotonated. This indicates that very likely a compromise has to be found between achieving optimal drug loading, while maintaining the activity of the drugs. We therefore incubated both drug molecules at a range of $\mathrm{pH}(5-9)$ and temperatures $\left(4{ }^{\circ} \mathrm{C}\right.$ vs. $25^{\circ} \mathrm{C}$ ) for 3 days and then evaluated their cytotoxicity by means of MTT cell viability assays.
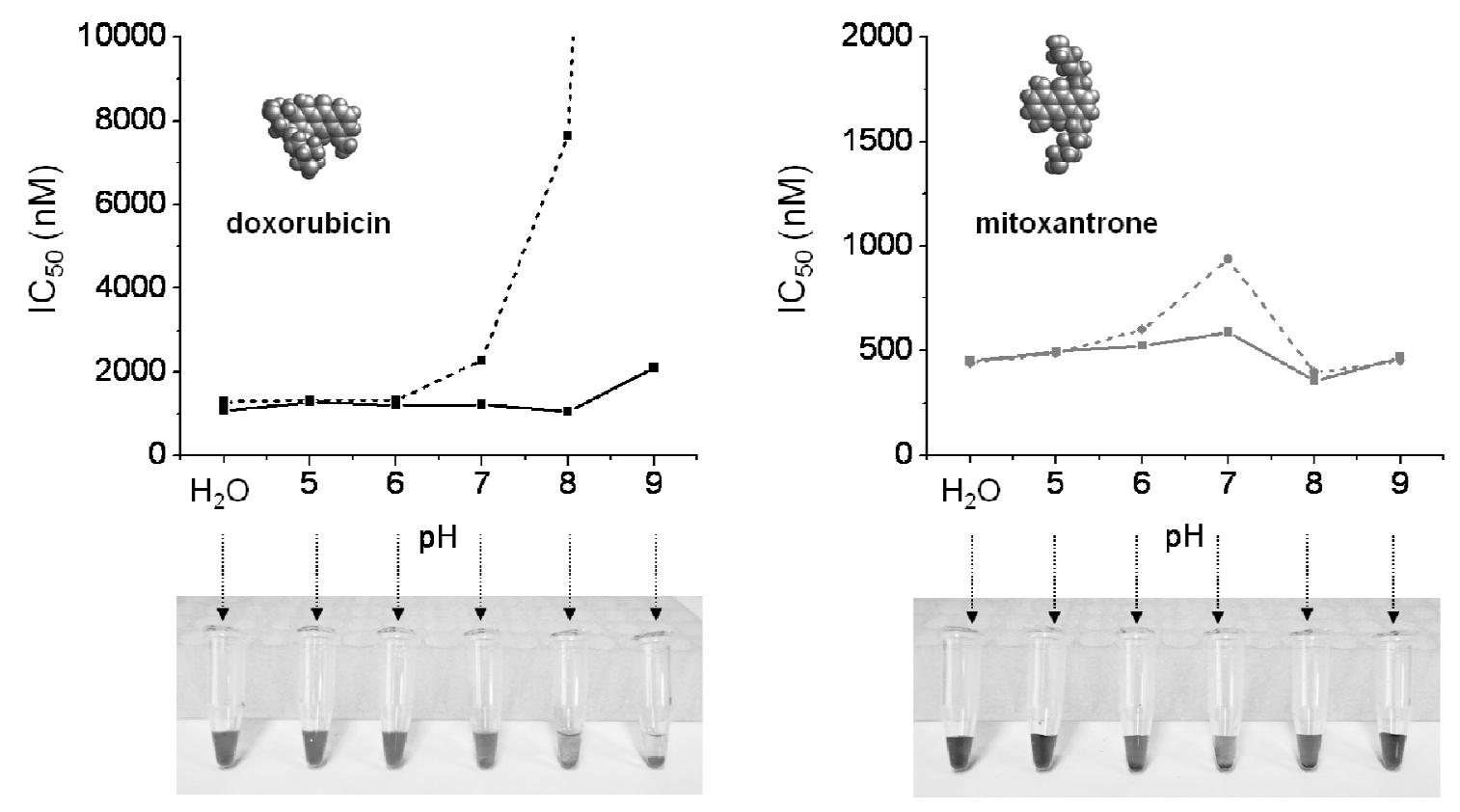

Figure 2 Therapeutic efficacy of doxorubicin and mitoxantrone after a 3-day incubation period at $\mathrm{pH} 5-9$ at $4{ }^{\circ} \mathrm{C}$ in the dark (solid lines) or at $25^{\circ} \mathrm{C}$ in daylight (dashed lines). The corresponding photographs show the respective drug solutions after incubation in daylight to demonstrate the visible aggregation effects.

Figure 2 shows how the cytotoxicity of the drugs, indicated by $\mathrm{IC}_{50}$ values, was affected by $\mathrm{pH}$. Doxorubicin incubated at $25{ }^{\circ} \mathrm{C}$ in daylight was unstable above $\mathrm{pH} 6$ and rendered entirely inactive at $\mathrm{pH} 9$. When the same solutions were incubated at $4{ }^{\circ} \mathrm{C}$ in the dark, however, doxorubicin did not lose its activity up to $\mathrm{pH} 8$ but lost some activity at $\mathrm{pH}$ 9. This 
is in accordance with the literature [17] and shows that degradation of doxorubicin is considerably accelerated by light and high $\mathrm{pH}$, possibly due to the promotion of oxidation reactions or the formation of drug polymers, which are incapable of penetrating the cellular membrane [18]. The self-aggregation of neutral antracycline molecules by $\pi$-stacking is consistent with our studies, which indicated that doxorubicin forms visible agglomerates above $\mathrm{pH} 7$, with the extent of agglomeration correlating with a loss of activity (photograph beneath the diagram in Figure 2). In contrast, mitoxantrone was stable over the 3-day incubation period for all $\mathrm{pH}$ values (Figure $2 \mathrm{~b}$ ), although some loss of activity was observed at $\mathrm{pH} 7$ when incubated in daylight at $25{ }^{\circ} \mathrm{C}$ in light, but not at $4{ }^{\circ} \mathrm{C}$ in darkness. Interestingly, the drug also tended to precipitate at $\mathrm{pH} 7$ (and, to a lesser extent, at $\mathrm{pH} 6$ or 8), which correlated with the loss of activity at this $\mathrm{pH}$. However, compared to doxorubicin this effect was much less marked, which is consistent with the fact that mitoxantrone solutions form precipitates when kept at low temperatures, whilst maintaining the cytotoxic effect [16]. In conclusion, drug binding experiments should be performed at low temperatures and under protection from light to maintain drug activity and, for doxorubicin, at $\mathrm{pH} 8$ or lower.

\subsubsection{Effect of pH on drug binding}

Next, we investigated the influence of the $\mathrm{pH}$ on drug binding. Both doxorubicin and mitoxantrone are able to attach to the surface of carbon nanotubes by $\pi-\pi$ interactions due to their inherent aromatic structure. In addition, both drug molecules contain $\mathrm{pH}$-sensitive amine groups, which makes their binding to nanotubes $\mathrm{pH}$-dependent (enhanced at high $\mathrm{pH}$ and reduced at low $\mathrm{pH}[5])$. This potentially allows for drug release in acidic endosomes and the microenvironment of tumors. To evaluate the $\mathrm{pH}$ dependence of drug binding, oxSWCNTs were incubated with the two drugs at pH 5 to 9 for 18 hours, after which the samples were 
filtered and the quantity of unbound drug in the filtrate measured by UV/vis absorption spectroscopy. Samples without nanotubes (also from pH 5-9) served as controls.

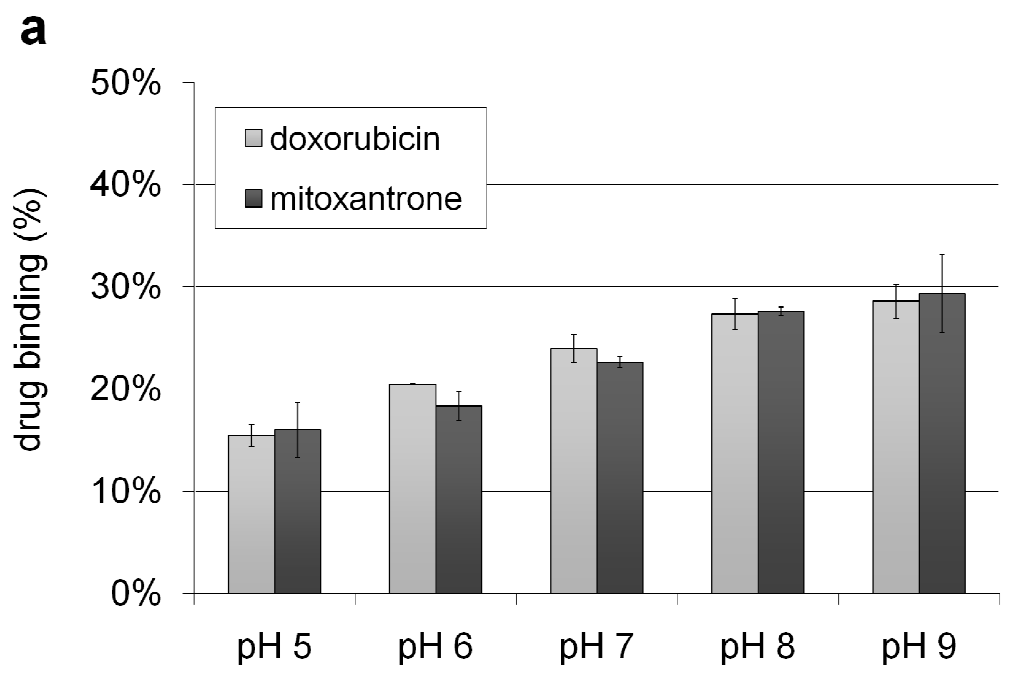

b

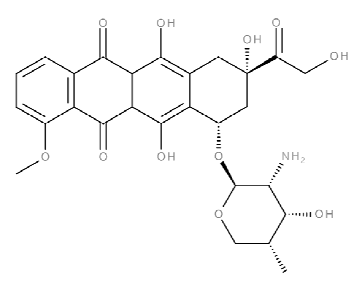

doxorubicin

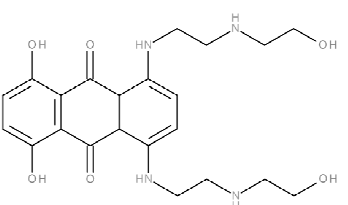

mitoxantrone

Figure 3 a) Binding of doxorubicin and mitoxantrone to oxSWCNTs at $\mathrm{pH}$ ranging from 5 to 9: The higher the $\mathrm{pH}$, the higher the drug binding. b) Chemical structures of doxorubicin and mitoxantrone.

Figure 3 shows that, as expected, both doxorubicin and mitoxantrone bind to nanotubes to a greater extent with increasing $\mathrm{pH}$, with maximal binding at $\mathrm{pH} 8-9$. This is due to the majority of amino groups being deprotonated at these $\mathrm{pH}$ (having $\mathrm{pKa}$ values between 8.3 and 8.6 [19]), making them more hydrophobic and capable of binding to the nanotube surface by $\pi-\pi$ interactions. In combination with the results of the previous experiment, it can be concluded that a $\mathrm{pH}$ of 8 is optimal for the binding of doxorubicin to oxSWCNTs and a $\mathrm{pH}$ of 9 is optimal for mitoxantrone, provided that the binding reaction is carried out at $4{ }^{\circ} \mathrm{C}$ in the dark.

However, we noticed that the nanotubes precipitated out of solution during the drug-binding incubation. This was not surprising, as it is well-known that oxidised carbon nanotubes give 
rise to electrostatic interactions with salts, such as the two anticancer drugs investigated here, which can impair the dispersion stability due to charge neutralisation [20]. Precipitation did not influence the efficacy of drug binding; but it is of course essential that any clinical formulation remains stable in the circulation, so dispersion stability is critical. In a previous study we have shown that the dispersion stability of oxidised nanotubes and also their biocompatibility toward cancer cells can be improved by covalent conjugation to polyethylene glycol (PEG) [12]. PEGylation is also a widely-used pharmaceutical formulation strategy in clinical settings, as it reduces immunogenicity and non-specific interactions with plasma proteins, while concomitantly prolonging blood circulation times. We, therefore, attempted to optimise dispersion stability of PEGylated oxSWCNTs in the presence of the drugs while monitoring the degree of drug loading.

\subsubsection{Effect of the type of PEG on drug loading and dispersion stability}

Five different types of PEG molecules were tested with regard to their effect on drug binding and dispersion stability. This included a homobifunctional, amine-terminated PEG (PEG 2000- $\mathrm{NH}_{2}$ ), two heterobifunctional PEGs of different chain lengths (PEG 440-COOH and PEG 3000-COOH), and a branched PEG with four amine-terminated arms (branched PEG 2500- $\mathrm{NH}_{2}$ ), all of which were covalently linked to oxSWCNTs by one of their amine groups by carbodiimide-activated coupling. Note that this type of coupling reaction is not quantitative and that amine-terminated PEG may also adsorb to oxidised nanotubes via acidbase zwitterionic interactions, as shown by Huang et al. [21] and Marega et al. [22]. As a fifth candidate, we investigated an amine-terminated phospholipid-PEG (PL-PEG2000- $\mathrm{NH}_{2}$ ), which is widely used as a dispersion agent for carbon nanotubes [23, 24]. In this case the functionalisation was based on non-covalent interactions promoted by the binding of the phospholipid-moiety to the nanotube surface. The ideal PEG candidate should optimally 
stabilise nanotube dispersions without impairing drug binding through steric hindrance or repulsive electrostatic interactions.

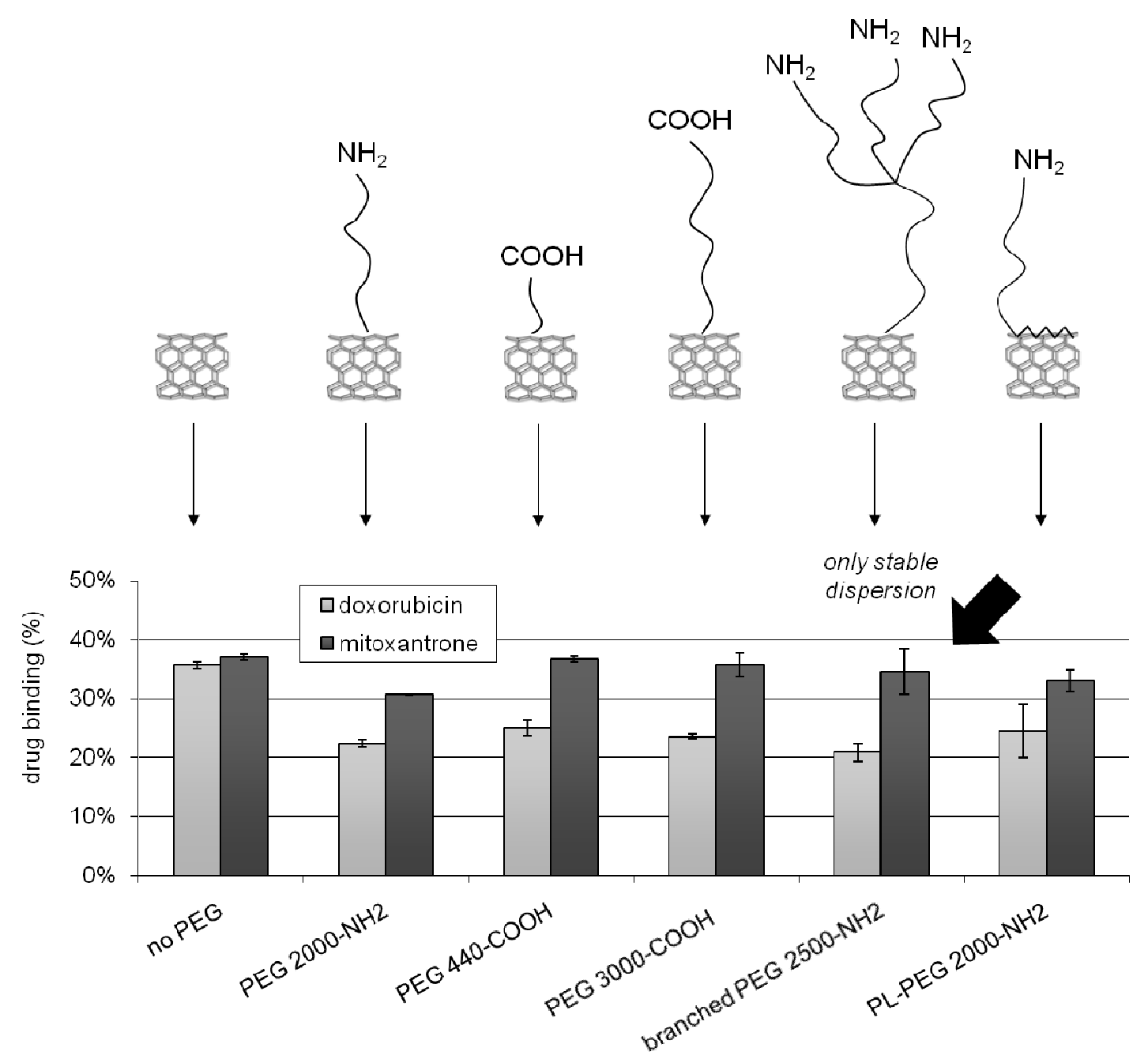

Figure 4 Effect of the PEG type on drug binding and dispersion stability: Only one PEG candidate - branched PEG 2500- $\mathrm{NH}_{2}$ - was able to promote a stable dispersion after addition of the drugs, whereas in all other cases, the nanotubes precipitated out of solution.

Figure 4 shows the effect of the different PEG types on drug binding and dispersion stability. PEGylation reduced the binding of doxorubicin by approximately $10 \%$, whereas the binding of mitoxantrone was only slightly reduced. Drug binding for each of the PEG molecules was very similar; however, only the oxSWCNT sample functionalised with branched PEG 
(branched PEG 2500- $\mathrm{NH}_{2}$ ) remained stable, whereas in all other cases the nanotubes had precipitated out of solution. Based on these results, we thus decided to use branched PEG 2500- $\mathrm{NH}_{2}$ for all further experiments. The combined molecular weight of the PEG molecules attached is $10 \mathrm{kDa}$ (4 branches of $2.5 \mathrm{kDa}$ each); a value which was also found optimal for the prevention of nonspecific protein adsorption and favourable cellular responses in a study by $\mathrm{He}$ et al. [25].

\subsubsection{Effect of the degree of PEGylation on drug loading}

The optimal PEG molecule (branched PEG 2500- $\mathrm{NH}_{2}$ ) was conjugated to oxSWCNTs at various concentrations to investigate the effect of PEG density on drug loading and dispersion stability. In this experiment, the nanotube concentration was kept constant, while branched PEG was added at amounts ranging from $5 \mu \mathrm{mol}$ to $0.1 \mu \mathrm{mol}$. After the conjugation reaction, unreacted PEG molecules were removed by filtration through $0.2 \mu$ m polycarbonate filters and repeated washing.

a

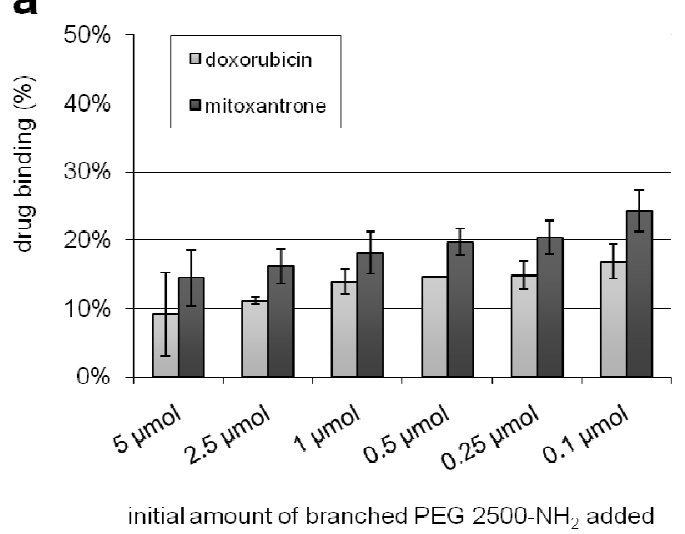

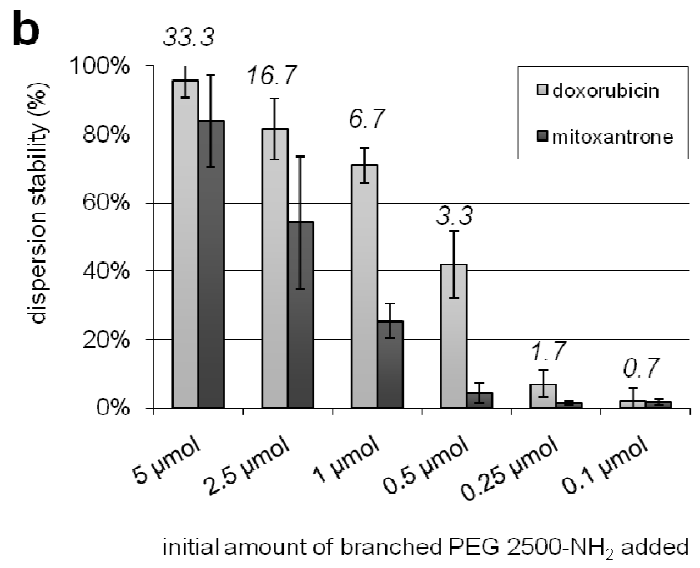

Figure 5 Impact of the PEG density on drug binding (a) and dispersion stability (b). Only the highest initial amount of PEG added $(5 \mu \mathrm{mol})$ resulted in sufficient dispersion stability after addition of the drugs, although this reduced drug binding by about $40 \%$. The numbers in 
italics above the columns in (b) indicate the ratio of PEG molecules to acidic sites on the oxSWCNTs.

As illustrated in Figure 5a, the more PEG was added initially, the lower was the drug binding. Although we did not determine the actual amounts of PEG attached to the oxSWCNTs after the coupling reaction, we presume that adding a higher amount of PEG during the reaction leads to a higher PEG density of the final product, which may impair drug binding due to sterical hindrance. Dispersion stability, on the other hand, significantly improved with increasing initial amounts of PEG used (Figure 5b); in fact only the highest amount of PEG added ( $5 \mu \mathrm{mol}$ or a 33-fold molar excess) was able to maintain a sufficiently stable dispersion after addition of the drugs. When comparing the two drugs, mitoxantroneloaded oxSWCNTSPEG (mito-oxSWCNTSPEG) were less stable than doxorubicin-loaded

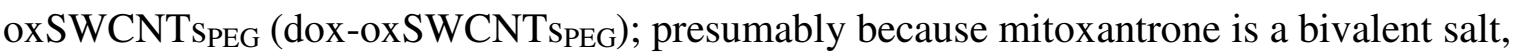
whereas doxorubicin is monovalent. For subsequent experiments, branched PEG 2500- $\mathrm{NH}_{2}$ was used at an initial amount of $5 \mu \mathrm{mol}$ to ensure maximal dispersion stability, although this compromised drug binding by about $40 \%$. Furthermore, we used a drug/oxSWCNT $\mathrm{PEG}_{\mathrm{P}}$ weight ratio of approximately 1:2 in order to obtain quantitative drug binding and thus eliminating the need for a filtration step to remove unbound drug, which corresponded to a final drug concentration of $25 \mu \mathrm{M}$ (or $14.5 \mu \mathrm{g} / \mathrm{mL}$ doxorubicin and $12.9 \mu \mathrm{g} / \mathrm{mL}$ mitoxantrone, respectively) and a final oxSWCNT ${ }_{\text {PEG }}$ concentration of $25 \mu \mathrm{g} / \mathrm{mL}$. The absence of free drug (at zero time) is demonstrated in the next section.

\subsection{Drug release over time at different conditions}

The release of both doxorubicin and mitoxantrone should be promoted at low $\mathrm{pH}$ due to their amine functionalities, which render them hydrophilic at low $\mathrm{pH}$ and hydrophobic at high $\mathrm{pH}$. 
To confirm this effect at $\mathrm{pH} 5.5$, which is the approximate $\mathrm{pH}$ the drug delivery sytem would encounter in the endosomal pathway, we incubated dox-oxSWCNTSPEG or mitooxSWCNTSPEG in buffers at pH 7.4 or 5.5 for 3 days. After every $24 \mathrm{~h}$, the samples were filtered and the released drug in the eluates was measured by UV/vis absorption spectroscopy. Drug release was also assayed in cell culture growth medium (buffered at $\mathrm{pH}$ 7.4), mimicking the conditions of a typical cell viability assay.

a

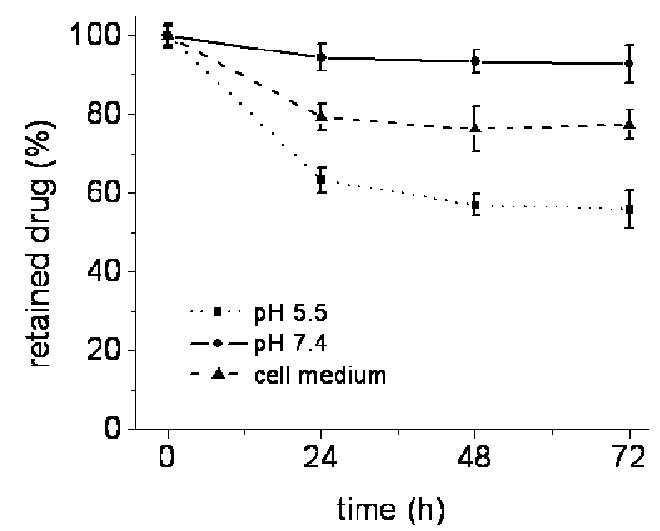

b

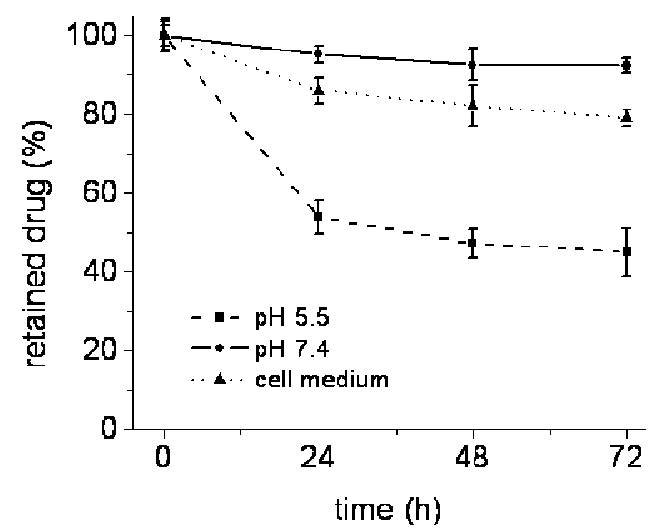

Figure 6 Release of the drugs doxorubicin (a) and mitoxantrone (b) from their nanotube carrier at pH 5.5 and $\mathrm{pH} 7.4$ and in cell culture medium.

As observed in Figure 6, the drugs were gradually released from their nanotube carrier at $\mathrm{pH}$ 5.5 with $44 \%$ of doxorubicin and $55 \%$ of mitoxantrone released after $72 \mathrm{~h}$. In contrast, only $7 \%$ of doxorubicin and $8 \%$ of mitoxantrone was released at $\mathrm{pH} 7.4$ after the same time. Incubation of the drug-oxSWCNT $\mathrm{PEG}_{\mathrm{PE}}$ conjugates in cell growth medium did however release significant quantities of drug: $23 \%$ of doxorubicin and $21 \%$ of mitoxantrone by $72 \mathrm{~h}$. This suggests that bound drugs were gradually being displaced on the nanotube surface by components of the cell culture medium during the incubation, most probably by serum proteins from the fetal calf serum component. This potentially allows for extracellular release 
of the drug from the nanotube carrier and its subsequent diffusion through the cell membrane without its nanocarrier, although this would only occur for long blood circulation times (1-3 days).

\subsection{Intracellular distribution of $C N T_{P E G^{-}}$doxorubicin conjugates}

Hela cells were incubated with dox-oxSWCNTS $\mathrm{SEG}_{\mathrm{PE}}$ for $4 \mathrm{~h}$ (Figure 7) and drug uptake monitored by confocal microscopy, taking advantage of the inherent fluoresence of doxorubicin
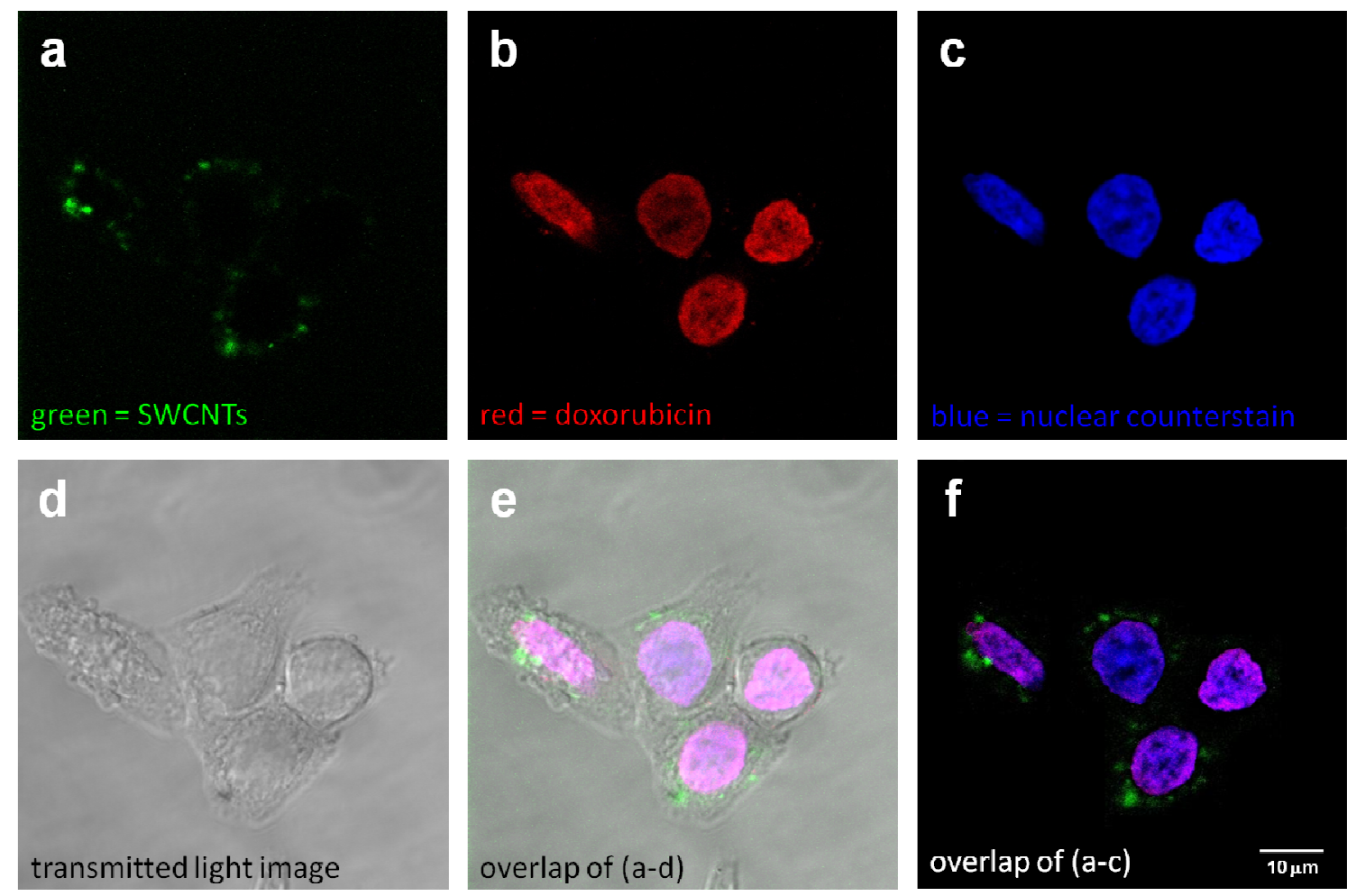

Figure 7 Confocal microscopy image of Hela cells after $4 \mathrm{~h}$ incubation with fluorescein-

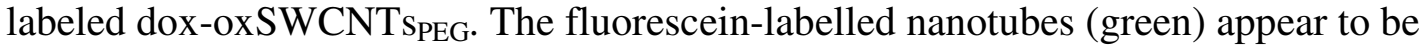
confined in discrete spots around the nucleus, indicating localisation within endosomes. Doxorubicin (red), on the other hand, is observed in the nucleus (counterstained in blue) and does not colocalise with the nanotubes, suggesting its release inside the cell. Cell boundaries are visible in the transmitted light image (d). 
The confocal images show that doxorubicin (red, Figure 7b) was entirely located in the cell nucleus (counterstained with ToPro 3, in blue, Figure 7c), proving its release from the nanotubes (labelled with fluorescein, in green), which were distributed as discrete spots in the cytoplasm (Figure 7a), indicating localisation within endosomes. This suggests an endocytotic, energy-dependent uptake mechanism, which would lead to the engulfment of the drug-SWCNT-complexes in endosomes and subsequent release of the drug due to the lower endo-/lysosomal pH (as also shown in Figure 6). The drug would then translocate to the cell nucleus to exert its cytotoxic action; interference with DNA replication [26]. The exact uptake mechanism and fate of CNTs inside cells is currently further investigated in our laboratory and will be published separately $[27,28]$. It is important to note that a small amount of doxorubicin has been found to detach from its CNT carrier extracellularly during incubation in cellular growth medium (Figure 6) and can potentially diffuse through the cell membrane on its own.

\subsection{Effect of dispersion stability on uptake and activity of the drug-SWCNT complexes}

We first aimed to investigate whether the dispersion stability of drug-loaded oxSWCNTs affects the drugs' therapeutic activity on cultured cells. Two types of oxSWCNTs were used, oxSWCNTs reacted with 5 mM PEG and "naked" oxSWCNTs, associated with dispersion stabilities of $90-100 \%$ and $0 \%$, respectively. In order to evaluate cytotoxicity, we used both the MTT and the WST assay and compared the results of the two, as the former is known to cause false positive test results due to interactions of the hydrophobic end product MTTformazan with the CNT surface, which can occur outside as well as inside cells [11]. The WST assay follows the same assay principle as the MTT assay, but its end product is hydrophilic and therefore not prone to attach to the surface of CNTs (please see the supporting information for a full comparison between the two assays and the impact on this 
experiment). In brief, we found that the MTT and WST assay lead to comparable results if the CNT surface is fully occupied (e.g. in the case of drug-loaded, PEGylated oxSWCNTs), but that the MTT assay leads to false positive results if parts or the whole CNT surface is available to bind MTT-formazan.

Figure 8a and $\mathbf{b}$ display the fitted dose-response curves obtained as a result of the performed WST viability assays. Both oxSWCNTs (precipitated in cell medium) and oxSWCNTSPEG (stable in cell medium) were non-toxic over the whole dose range (see Figure S2 in the supporting information for the dose-response curve of oxSWCNTSPEG). When comparing the drug-loaded samples, there was no significant difference between the stable, well-dispersed sample (drug-loaded oxSWCNTS PEG $_{\text {) }}$ and the unstable sample (drug-loaded oxSWCNTs), possibly due to the cells' ability to take up precipitates of nanotubes [3] and premature drug release in the cell medium (Figure 6). In comparison to the free drugs, drug-loaded nanotubes were less cytotoxic $\left(\mathrm{IC}_{50}\right.$ values of doxorubicin only/oxSWCNTS PEG $_{2}=239 \pm 14 \mathrm{nM} / 432 \pm 46$ $\mathrm{nM}, \mathrm{IC}_{50}$ values of mitoxantrone only/ mito-oxSWCNTSPEG $\left.=133 \pm 6 \mathrm{nM} / 248 \pm 12 \mathrm{nM}\right)$. This is likely due to drug molecules taken up by passive transport being free to translocate directly to the nucleus, where they exert cytotoxicity, whereas drug molecules complexed to carbon nantubes are released only after encountering the lower $\mathrm{pH}$ inside endosomes and lysosomes and so lower amounts reach the nucleus to excert a cytotoxic effect. The next step was to investigate, whether the attachment of a targeting agent could improve the complexes' cytotoxicity and additionally provide specificity to cancerous cells. We chose folic acid as a targeting agent, as the folate-receptor is significantly upregulated by a broad spectrum of human cancers, in some cases by two orders of magnitude, facilitating cellular internalisation of folate-conjugated nanocarriers by receptor-mediated endocytosis [10, 29]. Additionally, non-cancerous cells only transport folate by this receptor but not folate conjugates of any type [30], which adds an extra level of specificity. Folic acid was covalently attached folate to the 
amine termini of the PEG chains, as described in the methodology, and Hela cells maintained in folate-depleted growth medium for several passages to induce overexpression of the folatereceptor. Subsequently, the cells were incubated with the folate-targeted drug-oxSWCNT $\mathrm{PEG}_{\mathrm{P}}$ complexes for $96 \mathrm{~h}$ as described above and cytotoxicity evaluated by means of the WST assay.

a

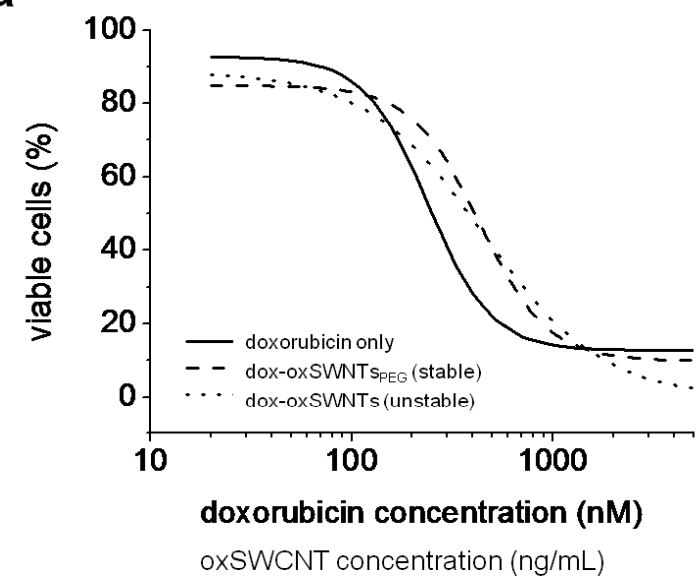

C

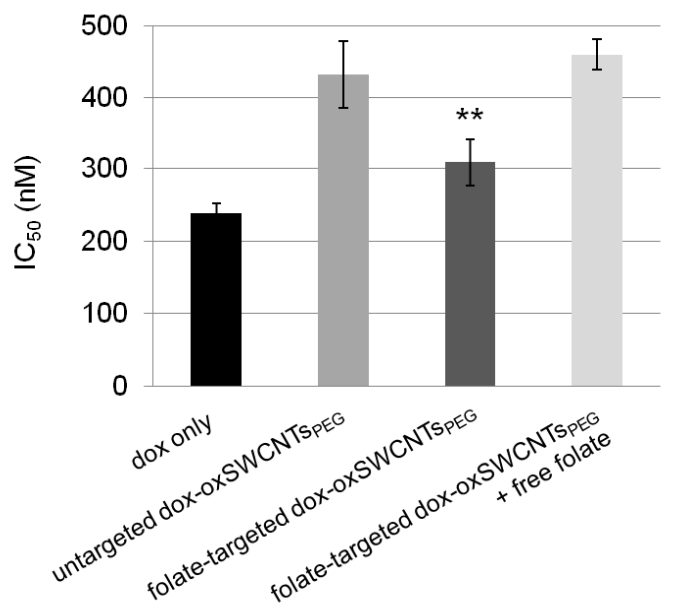

b

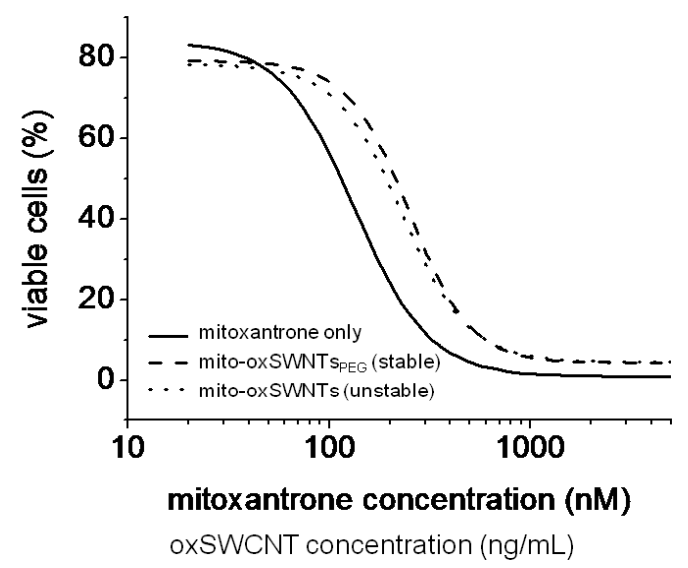

d

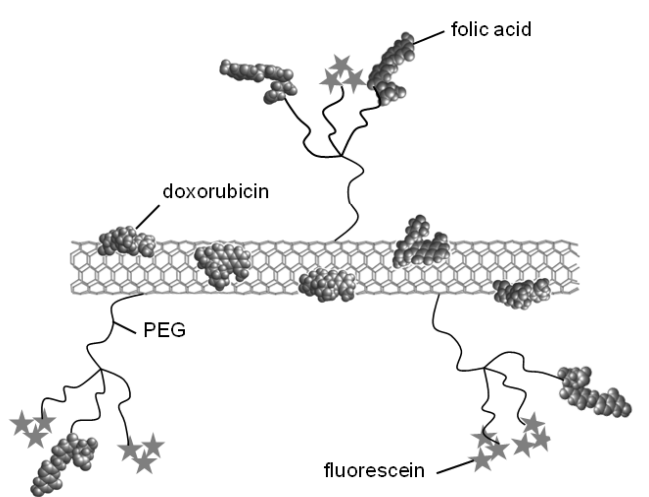

Figure 8 Fitted dose-response curves after 96 h-incubation of Hela cells with oxSWCNTs

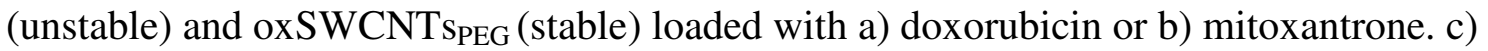
Therapeutic activity ( $\mathrm{IC}_{50}$ values) of folate-targeted dox-oxSWCNTs $\mathrm{SEG}_{\mathrm{PE}}$ and controls. Activity was significantly enhanced $\left(\mathrm{IC}_{50}=310 \pm 33 \mathrm{nM}, \mathrm{P}<0.05\right)$ when folate was 
conjugated to the PEG chains as a targeting agent. d) Schematic illustration of folate-targeted and fluorescently labeled dox-oxSWCNTSPEG.

Figure 8c displays the resulting $\mathrm{IC}_{50}$ values: The system's therapeutic efficacy was significantly enhanced $\left(\mathrm{IC}_{50}=310 \pm 33 \mathrm{nM}, \mathrm{P}<0.05\right)$ when folate was conjugated to the $\mathrm{PEG}$ chains as a targeting agent compared to the untargeted system $\left(\mathrm{IC}_{50}=432 \pm 46 \mathrm{nM}\right)$, which might be due to enhanced endocytotic uptake through receptor-mediated endocytosis (as discussed above, drug release requires localisation of the drug-nanotube complexes inside endo- or lysosomes). When the folate-receptors were saturated with free folic acid, however, the efficacy became again similar to that of the untargeted system $\left(\mathrm{IC}_{50}=460 \pm 21 \mathrm{nM}\right)$, confirming the selectivity of the targeting approach and its advantage over using the free drug.

\section{Conclusions}

We have developed a carbon nanotube-mediated drug delivery system for two different anticancer drugs, affording high biological and chemical stability, high drug loading and selective cancer treatment in an in vitro scenario by an active targeting scheme. After finetuning the synthesis parameters to obtain maximal drug loading, while maintaining the dispersion stability of the system, we demonstrated $\mathrm{pH}$-dependent drug release in buffer solutions and confirmed cellular uptake of the nanovectors and intracellular drug release, by means of confocal microscopy. Finally, we evaluated the therapeutic efficacy of the system in cell viability assays and found that while drug-loaded nanotubes were less effective than the free drugs, attachment of the targeting agent folic acid significantly enhanced the efficacy and selectivity of the system. Keeping in mind that free doxorubicin and mitoxantrone are both highly effective in in vitro experiments due to their aqueous solubility and membrane 
permeability, this is an encouraging result. The targeted, drug loaded nanotubes are selective in contrast to the free drugs and additionally allow for sustained release, which is likely to reduce drug-related side effects in animal models and clinical studies. Overall, our study demonstrates the potential of carbon nanotubes as a multimodal drug delivery system and presents a functionalisation scheme that is able to overcome many of the problems encountered in this area of application.

\section{Acknowledgements}

This work has been performed in the framework of the FP6 Marie Curie Research Training Network “CARBIO” (RTN-CT-2006-035616) funded by the European Union.

\section{References}

[1] Alderton PM, Gross J, Green MD. Comparative study of doxorubicin, mitoxantrone, and epirubicin in combination with ICRF-187 (ADR-529) in a chronic cardiotoxicity animal model. Cancer Research. 1992 Jan 1;52(1):194-201.

[2] Kostarelos K, Lacerda L, Pastorin G, Wu W, Wieckowski S, Luangsivilay J, et al. Cellular uptake of functionalized carbon nanotubes is independent of functional group and cell type. Nature Nanotechnology. 2007 Feb;2(2):108-13.

[3] Mu QX, Broughton DL, Yan B. Endosomal leakage and nuclear translocation of multiwalled carbon nanotubes: developing a model for cell uptake. Nano Letters. 2009 Dec;9(12):4370-5.

[4] Heister E, Neves V, Tîlmaciu C, Lipert K, Sanz Beltrán V, Coley H, et al. Triple functionalisation of single-walled carbon nanotubes with doxorubicin, a monoclonal antibody, and a fluorescent marker for targeted cancer therapy. Carbon. 2009;47(9):2152-60. 
[5] Liu Z, Sun XM, Nakayama-Ratchford N, Dai HJ. Supramolecular chemistry on watersoluble carbon nanotubes for drug loading and delivery. ACS Nano. 2007 Aug;1(1):50-6.

[6] Ali-Boucetta H, Al-Jamal KT, McCarthy D, Prato M, Bianco A, Kostarelos K. Multiwalled carbon nanotube-doxorubicin supramolecular complexes for cancer therapeutics. Chemical Communications. 2008(4):459-61.

[7] Zhang XK, Meng LJ, Lu QG, Fei ZF, Dyson PJ. Targeted delivery and controlled release of doxorubicin to cancer cells using modified single wall carbon nanotubes. Biomaterials. 2009 Oct;30(30):6041-7.

[8] Liu Z, Fan AC, Rakhra K, Sherlock S, Goodwin A, Chen X, et al. Supramolecular stacking of doxorubicin on carbon nanotubes for in vivo cancer therapy. Angew Chem Int Ed Engl. 2009;48(41):7668-72.

[9] Li RB, Wu R, Zhao L, Wu MH, Yang L, Zou HF. P-glycoprotein antibody functionalized carbon nanotube overcomes the multidrug resistance of human leukemia cells. ACS Nano. 2010 Mar;4(3):1399-408.

[10] Russell-Jones G, McTavish K, McEwan J, Rice J, Nowotnik D. Vitamin-mediated targeting as a potential mechanism to increase drug uptake by tumours. Journal of Inorganic Biochemistry. 2004 Oct;98(10):1625-33.

[11] Wörle-Knirsch JM, Pulskamp K, Krug HF. Oops they did it again! Carbon nanotubes hoax scientists in viability assays. Nano Letters. 2006 Jun;6(6):1261-8.

[12] Heister E, Lamprecht C, Neves V, Tilmaciu C, Datas L, Flahaut E, et al. Higher dispersion efficacy of functionalized carbon nanotubes in chemical and biological environments. ACS Nano. 2010 May 25;4(5):2615-26. 
[13] Verdejo R, Lamoriniere S, Cottam B, Bismarck A, Shaffer M. Removal of oxidation debris from multi-walled carbon nanotubes. Chemical Communications. 2007 Feb 7(5):513-5.

[14] Beijnen JH, Vanderhouwen OAGJ, Underberg WJM. Aspects of the degradation kinetics of doxorubicin in aqueous solution. International Journal of Pharmaceutics. 1986 Oct;32(2-3):123-31.

[15] Wang DP, Liang GZ, Tu YH. Stability of mitoxantrone hydrochloride in solution. Drug Development and Industrial Pharmacy. 1994;20(11):1895-903.

[16] Cancer Care Nova Scotia. Drug Monograph Mitoxantrone. Systemic Therapy Manual for Cancer Treatment 2010:208-10.

[17] Bouma J, Beijnen JH, Bult A, Underberg WJM. Anthracycline antitumor agents - a review of physicochemical, analytical and stability properties. Pharmaceutisch Weekblad-Scientific Edition. 1986 Apr 25;8(2):109-33.

[18] Williams BA, Tritton TR. Photoinactivation of anthracyclines. Photochemistry and Photobiology. 1981;34(1):131-4.

[19] Raghunand N, Mahoney BP, Gillies RJ. Tumor acidity, ion trapping and chemotherapeutics I. pH-dependent partition coefficients predict importance of ion trapping on pharmacokinetics of weakly basic chemotherapeutic agents. Biochemical Pharmacology. 2003 Oct 1;66(7):1219-29.

[20] Peng XJ, Jia JJ, Gong XM, Luan ZK, Fan B. Aqueous stability of oxidized carbon nanotubes and the precipitation by salts. Journal of Hazardous Materials. 2009 Jun $15 ; 165(1-3): 1239-42$.

[21] Huang WJ, Fernando S, Allard LF, Sun YP. Solubilization of single-walled carbon nanotubes with diamine-terminated oligomeric poly(ethylene glycol) in different functionalization reactions. Nano Letters. 2003 Apr;3(4):565-8. 
[22] Marega R, Aroulmoji V, Bergamin M, Feruglio L, Dinon F, Bianco A, et al. Twodimensional diffusion-ordered NMR spectroscopy as a tool for monitoring functionalized carbon nanotube purification and composition. ACS Nano. 2010 Apr;4(4):2051-8.

[23] Prencipe G, Tabakman SM, Welsher K, Liu Z, Goodwin AP, Zhang L, et al. PEGbranched polymer for functionalization of nanomaterials with ultralong blood circulation. Journal of the American Chemical Society. 2009 Apr 8;131(13):4783-7.

[24] Lamprecht C, Danzberger J, Lukanov P, Tilmaciu CM, Galibert AM, Soula B, et al. AFM imaging of functionalized double-walled carbon nanotubes. Ultramicroscopy. 2009 Jul;109(8):899-906.

[25] He QJ, Zhang JM, Shi JL, Zhu ZY, Zhang LX, Bu WB, et al. The effect of PEGylation of mesoporous silica nanoparticles on nonspecific binding of serum proteins and cellular responses. Biomaterials. 2010 Feb;31(6):1085-92.

[26] Momparler RL, Karon M, Siegel SE, Avila F. Effect of Adriamycin on DNA, Rna, and Protein-Synthesis in Cell-Free Systems and Intact-Cells. Cancer Research. $1976 ; 36(8): 2891-5$.

[27] Neves V, Heister E, Costa S, Tîlmaciu C, Borowiak-Palen E, Giusca C, et al. Uptake and release of double-walled carbon nanotubes by mammalian cells. Advanced Functional Materials. 2010;20(19):3272-9.

[28] Neves V. Carbon Nanotubes (CNT): Feasibility as nano-bio agents to target cancer. PhD thesis, University of Surrey. 2011.

[29] Lu Y, Sega E, Leamon CP, Low PS. Folate receptor-targeted immunotherapy of cancer: mechanism and therapeutic potential. Adv Drug Deliv Rev. 2004 Apr $29 ; 56(8): 1161-76$. 
[30] Byrne JD, Betancourt T, Brannon-Peppas L. Active targeting schemes for nanoparticle systems in cancer therapeutics. Advanced Drug Delivery Reviews. 2008 Dec 14;60(15):1615-26. 


\section{List of Figures}

Figure 9 Characterisation of the used oxSWCNTs by a) atomic force microscopy, b) Raman spectroscopy, and c) UV/vis absorption spectroscopy.

Figure 10 Therapeutic efficacy of doxorubicin and mitoxantrone after a 3-day incubation period at $\mathrm{pH} 5-9$ at $4{ }^{\circ} \mathrm{C}$ in the dark (solid lines) or at $25^{\circ} \mathrm{C}$ in daylight (dashed lines). The corresponding photographs show the respective drug solutions after incubation in daylight to demonstrate the visible aggregation effects.

Figure 11 a) Binding of doxorubicin and mitoxantrone to oxSWCNTs at $\mathrm{pH}$ ranging from 5 to 9: The higher the $\mathrm{pH}$, the higher the drug binding. b) Chemical structures of doxorubicin and mitoxantrone.

Figure 12 Effect of the PEG type on drug binding and dispersion stability: Only one PEG candidate - branched PEG 2500- $\mathrm{NH}_{2}$ - was able to promote a stable dispersion after addition of the drugs, whereas in all other cases, the nanotubes precipitated out of solution.

Figure 13 Impact of the PEG density on drug binding (a) and dispersion stability (b). Only the highest initial amount of PEG added $(5 \mu \mathrm{mol})$ resulted in sufficient dispersion stability after addition of the drugs, although this reduced drug binding by about $40 \%$. The numbers in italics above the columns in (b) indicate the ratio of PEG molecules to acidic sites on the oxSWCNTs. 
Figure 14 Release of the drugs doxorubicin (a) and mitoxantrone (b) from their nanotube carrier at $\mathrm{pH} 5.5$ and $\mathrm{pH} 7.4$ and in cell culture medium.

Figure 15 Confocal microscopy image of Hela cells after $4 \mathrm{~h}$ incubation with fluoresceinlabeled dox-oxSWCNTSPEG. The fluorescein-labelled nanotubes (green) appear to be confined in discrete spots around the nucleus, indicating localisation within endosomes. Doxorubicin (red), on the other hand, is observed in the nucleus (counterstained in blue) and does not colocalise with the nanotubes, suggesting its release inside the cell. Cell boundaries are visible in the transmitted light image (d).

Figure 16 Fitted dose-response curves after 96 h-incubation of Hela cells with oxSWCNTs

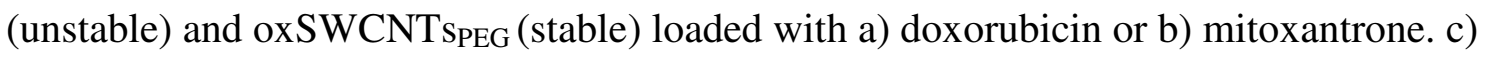
Therapeutic activity ( $\mathrm{IC}_{50}$ values) of folate-targeted dox-oxSWCNTSPEG and controls. Activity was significantly enhanced $\left(\mathrm{IC}_{50}=310 \pm 33 \mathrm{nM}, \mathrm{P}<0.05\right)$ when folate was conjugated to the PEG chains as a targeting agent. d) Schematic illustration of folate-targeted and fluorescently labeled dox-oxSWCNTSPEG. 